\title{
The Endophytic Strain Fusarium oxysporum Fo47: A Good Candidate for Priming the Defense Responses in Tomato Roots
}

\author{
Sébastien Aimé, Claude Alabouvette, Christian Steinberg, and Chantal Olivain
}

INRA, UMR 1347 Agroécologie, BP 86510, F-21065 Dijon cedex, France

Submitted 17 December 2012. Accepted 14 April 2013.

\begin{abstract}
The protective Fusarium oxysporum strain Fo47 is effective in controlling Fusarium wilt in tomato. Previous studies have demonstrated the role of direct antagonism and involvement of induced resistance. The aim of the present study was to investigate whether priming of plant defense responses is a mechanism by which Fo47 controls Fusarium wilt. An in vitro design enabled inoculation of the tap root with Fo47 and the pathogenic strain (Fol8) at different locations and different times. The expression levels of six genes known to be involved in tomato defense responses were quantified using reverse-transcription quantitative polymerase chain reaction (qPCR). Three genes-CHI3, $G L U A$, and $P R-1 a$-were overexpressed in the root preinoculated with Fo47, and then challenged with Fol8. The genes $G L U A$ and $P R-1 a$ were upregulated in cotyledons after inoculation of Fo47. Fungal growth in the root was assessed by qPCR, using specific markers for Fo47 and Fol8. Results showed a reduction of the pathogen growth in the root of the tomato plant preinoculated with Fo47. This study demonstrated that priming of tomato defense responses is one of the mechanisms of action of Fo47, which induces a reduced colonization of the root by the pathogen.
\end{abstract}

The species Fusarium oxysporum is one of the most represented fungal populations in soils all over the world. Among these soilborne populations of $F$. oxysporum, some strains are pathogenic, inducing damaging diseases in many crops. Other strains are nonpathogenic, and some strains among them are able to protect the plant against Fusarium wilt induced by pathogenic strains (forma specialis) specific to the plant species. The use of nonpathogenic $F$. oxysporum strains has been proposed as a biological way to control Fusarium diseases. The modes of action of the protective $F$. oxysporum strains are diverse (Alabouvette et al. 2009), including direct interactions with the pathogen and induced resistance of the plant. The protective strain $F$. oxysporum 47 (Fo47), isolated from a soil naturally suppressive to Fusarium wilts (Alabouvette 1986), efficiently controls Fusarium wilt of tomato (Supplementary Fig. S1) and is among the most studied biocontrol strains of $F$.

Corresponding author: C. Olivain; Telephone: +1 33 (0)3 806930 44; Fax: +1 33 (0)3 806932 24; E-mail: chantal.olivain@dijon.inra.fr

* The $\boldsymbol{e}$-Xtra logo stands for "electronic extra" and indicates that three supplementary figures are published online.

This article is in the public domain and not copyrightable. It may be freely reprinted with customary crediting of the source. The American Phytopathological Society, 2013. oxysporum (O'Donnell et al. 2009). Studies have focused on direct antagonism between Fo47 and pathogenic F. oxysporum and have demonstrated the role of competition for nutrients and root colonization (Couteaudier and Alabouvette 1990; Nagao et al. 1990; Olivain et al. 2006). Induced systemic resistance has been demonstrated by using a split-root system, which enables spatial separation through inoculation of the protective strain on one root from inoculation of the pathogenic strain on another root (Olivain et al. 1995). The resistance induced by Fo47 was not associated with a more abundant accumulation of transcripts encoding five pathogenesis-related (PR) proteins in tomato roots inoculated with Fo47 than in roots inoculated with the pathogenic strain (Aimé et al. 2008). These results prompted the hypothesis that Fo47 could induce a priming effect in tomato: the defense-related genes would only be upregulated after challenge inoculation by the pathogenic strain. Priming has been suggested as a mode of action for nonpathogenic strains of $F$. oxysporum protecting Asparagus officinalis against Fusarium wilt. He and associates (2002) reported that an activity of defense-related enzymes (peroxidase and phenylalanine ammonia-lyase) significantly enhanced in roots of nonpathogenic treated plants after challenge by the pathogenic strain $F$. oxysporum f. sp. asparagi. Paparu and associates (2007) observed the potentiation of two well-known defenserelated genes (catalase and PR-1) in a tolerant cultivar of banana when the roots were colonized by nonpathogenic F. oxysporum endophytes, then post-challenged with Rodopholus similis. Veloso and Díaz (2012) reported that, in plants pretreated with Fo47 and postinoculated with Verticillium dalhiae, three genes encoding a basic PR-1 protein, a class II chitinase, and a sesquiterpene cyclase had a higher expression level than the control in both the roots and the stem of Capsicum annuum.

The aim of this work was to address the hypothesis that Fo47 could potentiate the defense responses of tomato. An in vitro experimental system has been set up that enables an accurate inoculation of the root with the fungi, with a pathogenic $F$. oxysporum f. sp. lycopersici strain, Fol8, and the protective strain Fo47 being inoculated at different locations on the tap root. The expression of 10 genes known to be involved in tomato defense responses was studied using the reverse-transcription quantitative polymerase chain reaction (RT-qPCR). At different time intervals after root inoculation with either Fo47 or Fol8, accumulation of transcripts was followed in roots and also in cotyledons to detect a potential transduction of a signal to the aerial part of the plant. To detect potentiation of defense-related genes, transcript abundance was assessed in roots preinoculated or not with Fo47 and challenged with the pathogen. Reference genes were chosen by evaluating the expression stability of several tomato housekeeping genes (Expósito-Rodriguez et al. 2008; 
Ghareeb et al. 2011; Løvdal and Lilo 2009; Mascia et al. 2010) in our experimental conditions.

Several studies indicated that priming of defense reactions induced by plant growth-promoting rhizobacteria (Ahn et al. 2011; Pieterse et al. 1996) or Trichoderma spp. (Shoresh et al. 2005) applied to the roots resulted in a reduction of pathogen growth in the leaves. To determine whether defense responses induced by Fo47 could reduce the growth of the pathogen in root and, consequently, disease development, fungal colonization of the root was assessed by qPCR using specific molecular markers: Fo47 sequence-characterized amplified region (SCAR) (Edel-Hermann et al. 2011) and SIX1 marker for Fol8 (Rep et al. 2004).

\section{RESULTS}

\section{Selection of reference genes}

for normalizing gene expression in tomato plants during infection with $\boldsymbol{F}$. oxysporum.

To identify the reference gene or genes suitable for normalization of RT-qPCR data, a set of six candidate reference genes was selected from different functional categories in order to reduce the probability of a co-regulation. These genes encode an elongation factor $1-\alpha(E F 1)$, actin $(A C T)$, a $\beta$-tubulin $(T U B)$, a
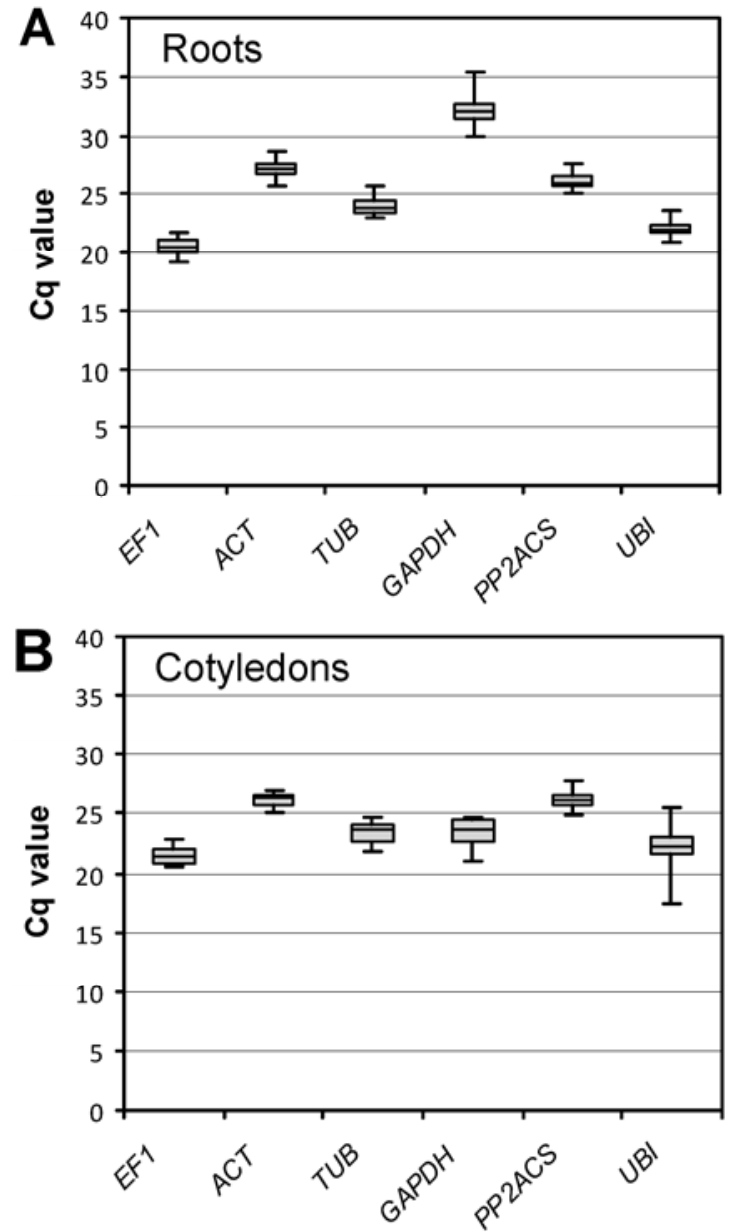

Fig. 1. Graphical representation of the expression level of six candidate reference genes in tomato seedlings cultivated in vitro and subjected to the different experimental conditions described in Materials and Methods. Box plots exhibit expression data as quantification cycle $(\mathrm{Cq})$ values for each gene from A, 26 root samples and $\mathbf{B}, 13$ cotyledon samples. Boxes indicate the 25th and 75th percentile (horizontal lines) and the line within the box represents the median. Minimum and maximum values are represented by whiskers. glyceraldehyde-3-phosphate dehydrogenase $(G A P D H)$, a protein phosphatase $2 \mathrm{~A}$ catalytic subunit $(P P 2 A C S)$, and ubiquitin $(U B I)$. The analysis of quantification cycle $(\mathrm{Cq})$ values of candidate reference genes via boxplots showed that, in root tissues (Fig. 1A), EFI and GAPDH presented the greatest difference, with $\mathrm{Cq}$ of 20.53 and 31.98, respectively, and GAPDH showing the highest variability. In cotyledon tissues (Fig. 1B), EFI and PP2ACS transcripts presented the most and least abundant accumulation levels, with the $U B I \mathrm{Cq}$ showing the highest variability. Using geNorm, a ranking of the tested genes was established according to the stability measure $\mathrm{M}$ from the most stable to the least stable. The analysis of expression stability verified the results obtained by boxplots of $\mathrm{Cq}$. In the roots (Fig. 2A), the most stable genes were $T U B$ and $P P 2 A C S$, with an $\mathrm{M}$ value of 0.27 . These two genes were suitable for normalization with a $\mathrm{V}$ value of 0.12 (Fig. 2B). In the cotyledons (Fig. 3A), the most stable genes were EF1 and PP2ACS, with an $\mathrm{M}$ value of 0.35 . The $\mathrm{V}$ value was 0.15 , equal to the recommended cut-off value (Fig. 3B), but inclusion of more genes did not improve the $\mathrm{V}$ value.

\section{Defense-related gene expression in tomato roots} after inoculation with either Fo47 or Fol8.

The considered genes encode an acidic extracellular chitinase $(C H I 3)$, a basic intracellular chitinase $(C H I 9)$, an acidic extracellular $\beta$-1,3-glucanase (GLUA), a basic intracellular $\beta$ 1,3-glucanase $(G L U B)$, a lipoxygenase $(L O X D)$, a PR-1 protein isoform PR-P6 $(P R-1 a)$, an extracellular endoproteinase $(P 69 G)$, a phenylalanine ammonia-lyase $(P A L)$, and two chalcone synthases (CHS1 and CHS2). These genes are involved in tomato defense responses (Danhash et al. 1993; Heitz et al. 1997; Kavroulakis et al. 2006; Van Kan et al. 1992) and play a role in the resistance of tomato diseases (Enkerli et al. 1993; Joosten and De Witt 1989; Uehara et al. 2010). They are also
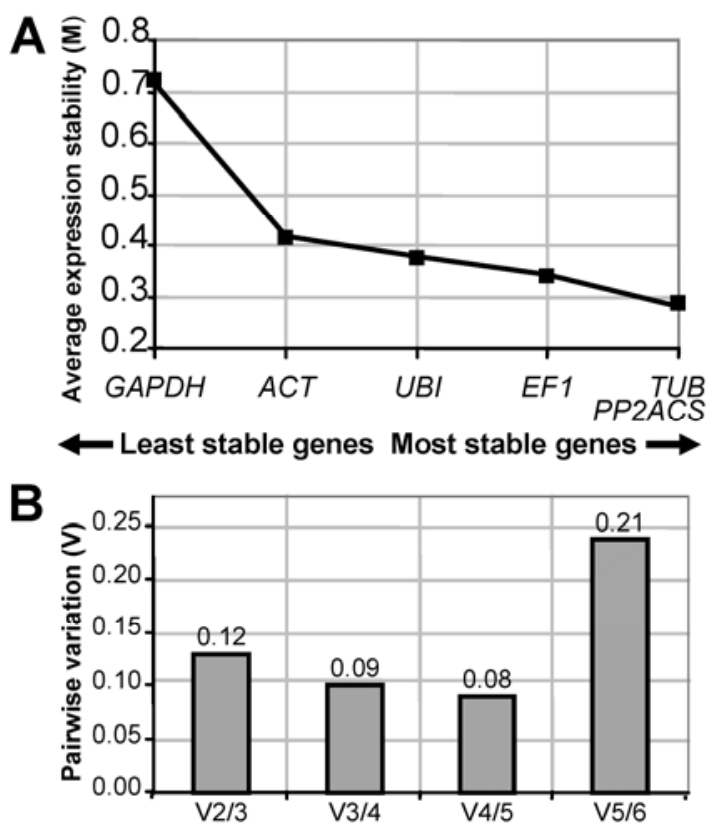

Fig. 2. Statistical analysis of expression stability of six candidate reference genes in tomato roots according to geNorm. Tomato seedlings were cultivated in vitro and subjected to different treatments. A, Average expression stability (M) was evaluated from 26 biological samples. A smaller value of average expression stability (M) indicates more stable expression. Any genes with $\mathrm{M}$ values greater than 1.5 were disqualified as internal control. B, Pairwise variation (V) analysis to determine the optimal number of reference genes required for reverse-transcription quantitative polymerase chain reaction data normalization. For any $\mathrm{V}_{n / n+1}<0.15$, it is unnecessary to include the $(n+1)$ th gene as the internal control. 
known to be involved in the resistance of different plant species against Fusarium wilts (Benhamou et al. 1989, 1990; Cachinero et al. 2002; Wróbel-Kwiatkowska et al. 2004).

In tomato roots, the expression of the genes $P 69 G, P A L$, $C H S 1$, and $C H S 2$ was too low to be quantified. At $48 \mathrm{~h}$ after inoculation of the tap root with either Fo47 or Fol8, none of the other considered genes showed an upregulation compared with the control. The induction of $C H I 9, G L U B, L O X D, C H I 3$, GLUA, and $P R-1 a$ genes was very weak (Fig. 4A), the relative transcript accumulation ranging from 0.3 for the $P R-1 a$ gene to 1.9 for the $\mathrm{CHI} 3$ gene in roots inoculated with Fol8 or Fo47, respectively. At $72 \mathrm{~h}$ after inoculation with either Fo47 or Fol8, the gene expression pattern was slightly different (Fig. 4B). The induction of CHI9, GLUB, and $L O X D$ genes was enhanced. The accumulation of transcripts was always higher after root inoculation with Fo47 than with Fol8, with the largest ratio of induction factor being obtained for GLUB gene ( $\times 4)$. The induction of $C H I 3, G L U A$, and $P R-1 a$ genes was low. The relative level of transcript accumulation varied from 0.7 for GLUA to 1.7 for $\mathrm{CHI} 3$ in roots inoculated with Fo47. At 96 h after inoculation with either Fo47 or Fol8, there was only a stimulated expression of the GLUA gene, the ratio of induction being 5.5 and 4.6 when the roots were inoculated with Fol8 or Fo47, respectively (Fig. 4C). The transcripts of the other genes accumulated at a low level and revealed a minimal expression of $C H I 9, G L U B, L O X D$, $C H I 3$, and $P R-1 a$ genes. Globally, these results indicate that fungal infection caused a slight modulation of the expression of the studied genes. The maximum level of transcript accumulation occurred for the GLUA gene at $96 \mathrm{~h}$ postinoculation with the pathogenic strain Fol8.
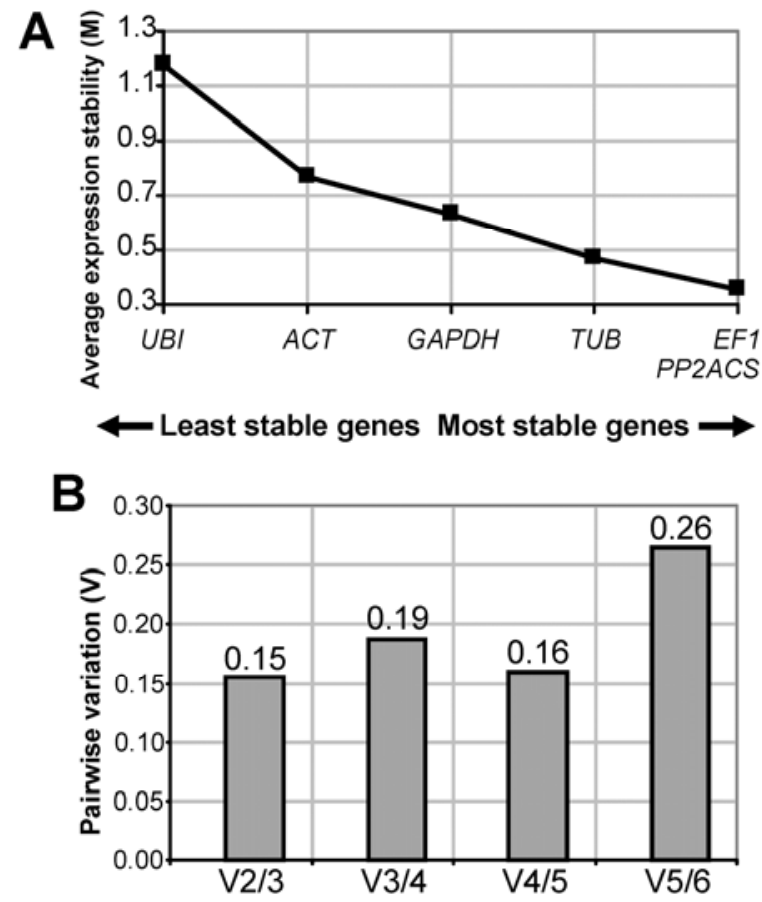

Fig. 3. Statistical analysis of expression stability of six candidate reference genes in tomato cotyledons according to geNorm. Tomato seedlings were cultivated in vitro and were subjected to different treatments. A, Average expression stability values (M) were evaluated from 13 biological samples. A smaller value of average expression stability (M) indicates more stable expression. Any genes with $\mathrm{M}$ values greater than 1.5 were disqualified as internal control. B, Pairwise variation (V) analysis to determine the optimal number of reference genes required for reverse-transcription quantitative polymerase chain reaction data normalization. For any $\mathrm{V}_{n / n+1}<0.15$, it is unnecessary to include the $(n+1)$ th gene as the internal control.
The biocontrol agent Fo47 potentiates the induction of $C H I 3, G L U A$, and PR-1a genes

in roots challenged with Fols.

To study potentiation of defense-related genes, the tap root of tomato seedlings was preinoculated or not with Fo47 and, $48 \mathrm{~h}$ later, inoculated with the pathogenic strain Fol8, with the two fungi being deposited at different locations on the root (Supplementary Fig. S2). The relative expression of defenserelated genes was assessed in tomato roots 24 and $48 \mathrm{~h}$ after inoculation of Fol8. At $24 \mathrm{~h}$ after root inoculation with Fol8, there was no difference in transcript levels of CHI3 and GLUA genes (Fig. 4D). The expression of CHI9, GLUB, LOXD, and $P R-1 a$ genes was increased; the stimulation of $C H I 9$ and $G L U B$ genes was significantly higher when roots were not inoculated with Fo47. At $48 \mathrm{~h}$ after root inoculation with Fol8 (Fig. 4E), the level of expression of $C H I 9, G L U B$, and $L O X D$ genes was comparable with that of the control plants, whatever the treatment. By contrast, the $C H I 3, G L U A$, and $P R-1 a$ genes showed differences in expression levels depending on the treatment. After inoculation with Fol8, the expression remained low in roots noninoculated with Fo47 but was greatly increased in roots preinoculated with Fo47. The expression levels of $\mathrm{CHI3}$, GLUA, and PR-1 $a$ genes were enhanced by 10.4-, 7.8- and 3.4fold, respectively, with the induction being 4.1-, 5.7-, and 1.9fold higher, respectively, than in the roots noninoculated with Fo47. The results showed that, among the genes considered, the $C H I 3, G L U A$, and PR-1 $a$ genes were upregulated in tomato roots preinoculated with Fo47.

\section{Defense-related gene expression in tomato cotyledons after inoculation with either Fo47 or Fol8.}

As in tomato roots, the expression of $P 69 G, P A L, C H S 1$, and $C H S 2$ genes in cotyledons was too low to enable quantification. At $48 \mathrm{~h}$ after root inoculation with Fo47 or Fol8, the expression of CHI9, GLUB, LOXD, CHI3, and GLUA genes in cotyledons was reduced and the expression of $P R$ - $1 a$ gene was at the detection threshold (data not shown). The highest level of transcripts occurred for the $L O X D$ gene, which was twofold that of the control plants. At $72 \mathrm{~h}$ after root inoculation with Fol8, only the expression of GLUB and GLUA genes was enhanced by a factor of 2.6 and 2.2, respectively (Fig. 5B). When the root was inoculated with Fo47, the expression of GLUA and $P R-1 a$ genes was stimulated, the ratio of induction being 5.1 and 4.3, respectively (Fig. 5B); no differences in the transcript levels of the other genes were recorded. At $96 \mathrm{~h}$ after root inoculation with Fol8, none of the studied genes were upregulated (Fig. 5C). When the root was inoculated with Fo47, the GLUA and PR-1 $a$ expression was increased 7.8- and 33.1 -fold, respectively, whereas the level of induction of the other genes was similar to that of the control plants. These results indicate that root inoculation with the protective strain Fo47 induced an upregulation of some genes in cotyledons.

\section{The biocontrol agent Fo47 reduces the development of the pathogenic strain Fol8 in root tissues.}

In order to determine whether defense responses induced by Fo47 are able to reduce root colonization by Fol8, specific markers able to quantify the growth of both Fo47 and Fol8 in roots were used. When inoculated alone, the kinetics of root colonization by Fo47 and Fol8 were the same (Fig. 6A). Microscopic observations (Supplementary Fig. S3) showed that, 12 days after inoculation, the pathogenic strain Fol8 was entering the xylem vessels. When Fol8 was inoculated on a root preinoculated with Fo47, the kinetics of colonization was affected by the presence of Fo47. In contrast, the kinetics of root colonization by Fo47 in the absence or presence of Fol8 was almost the same. 
The biomass of Fo47 and Fol8 in roots inoculated by each fungus alone or co-inoculated was assessed by calculation of the area under the colonization curve. Results showed that the biomass of Fol8 when inoculated alone was higher than that of Fo47 (Fig. 6B). Inoculation of Fol8 on a root preinoculated with Fo47 resulted in a significantly reduced colonization of the root by Fol8. The biomass of Fo47 was significantly reduced in the presence of Fol8 but to a lesser extent.

\section{DISCUSSION}

The aim of this study was to test the hypothesis that the protective strain Fo47 was priming the tomato defense responses.
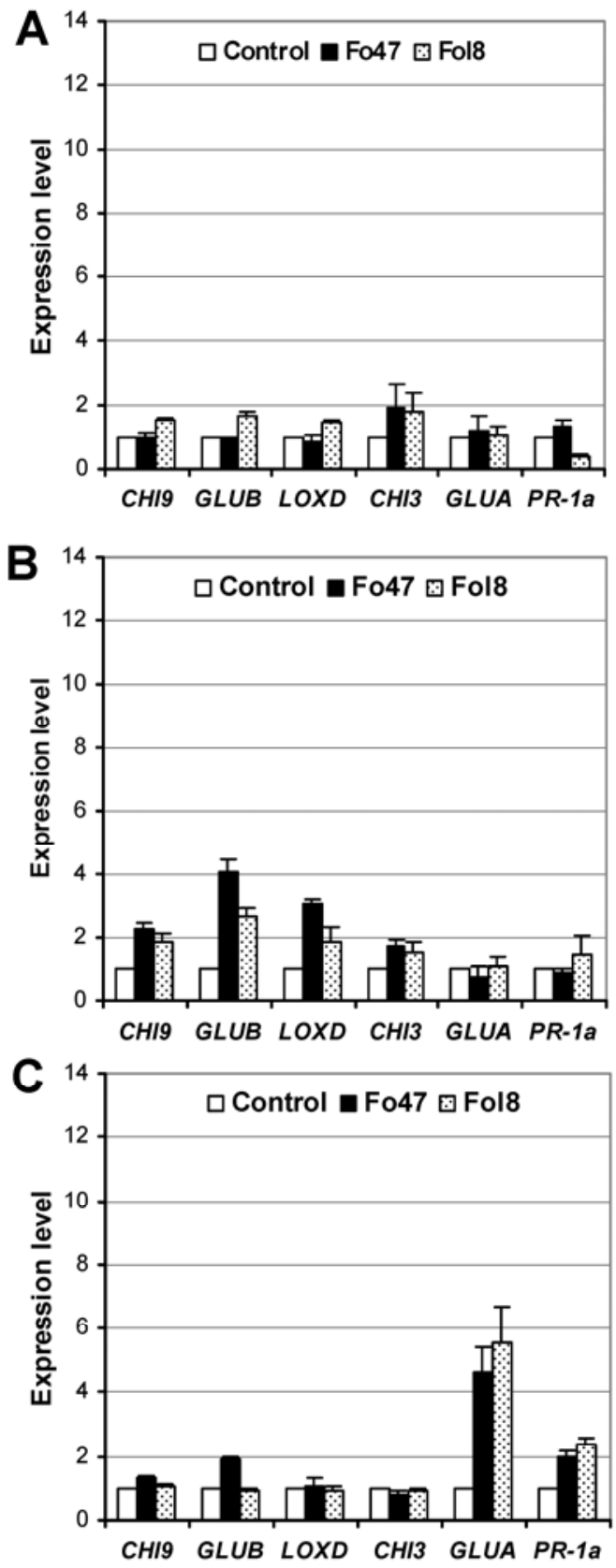

Priming is characterized by a faster and stronger expression of cellular defense responses that become activated only upon pathogen attack, resulting in an enhanced level of resistance to the pathogen (Van der Ent et al. 2009). Most of the studies dedicated to priming have considered chemical compounds (Kravchuk et al. 2011; Massoud et al. 2012; Zimmerli et al. 2000), plant growth rhizobacteria (Zamioudis and Pieterse 2012), or, less frequently, biological control fungi applied to Arabidopsis thaliana challenged by aerial pathogens (Tucci et al. 2011). Only limited studies were dedicated to defense responses induced in the root after inoculation with a biocontrol microorganism and challenge inoculation with a soilborne pathogen.
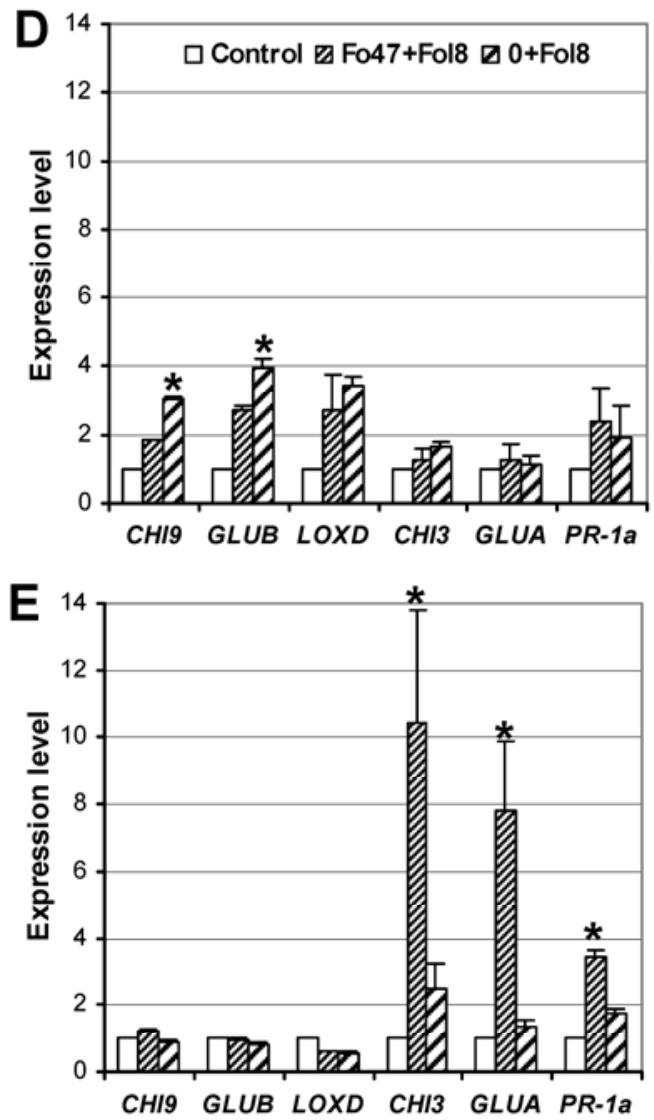

Fig. 4. Expression pattern of defense-related genes in tomato roots inoculated with germinated microconidia of Fusarium oxysporum. A, B, and C, Tap root was inoculated with either Fo47 or Fol8 and samples were collected A, 48; B, 72; and C, 96 h after inoculation. D and E, Tap root was inoculated (Fo47) or noninoculated (0) with Fo47 and, 2 days later, inoculated with Fol8 (+Fol8); samples were collected D, 24 and E, 48 h after Fol8 inoculation. Transcript accumulation of $C H I 9, G L U B, L O X D, C H I 3, G L U A$, and $P R-1 a$ genes was analyzed by reverse-transcription quantitative polymerase chain reaction. Results shown are from one representative experiment out of three. Bars represent mean expression levels normalized by the quantification cycle (Cq) geometric average from the genes TUB and PP2ACS and referred to the control (noninoculated roots) as $2^{-\Delta \Delta \mathrm{Cq}}$ with standard deviation bars (technical replicates $n=3$ ). Asterisks indicate statistically significant differences between roots preinoculated or noninoculated with Fo47 (Newman-Keuls test at $P=0.05)$. 
Results of this study showed that the expression pattern of defense-related genes in the root was weakly modified after inoculation with either Fo47 or Fol8. A higher expression of $L O X D$ and genes $C H I 9$ and $G L U B$, encoding intracellular PR proteins, was observed $72 \mathrm{~h}$ after inoculation, although genes GLUA and $P R-1 a$, encoding extracellular proteins, were overexpressed only $96 \mathrm{~h}$ postinoculation. These two genes were the
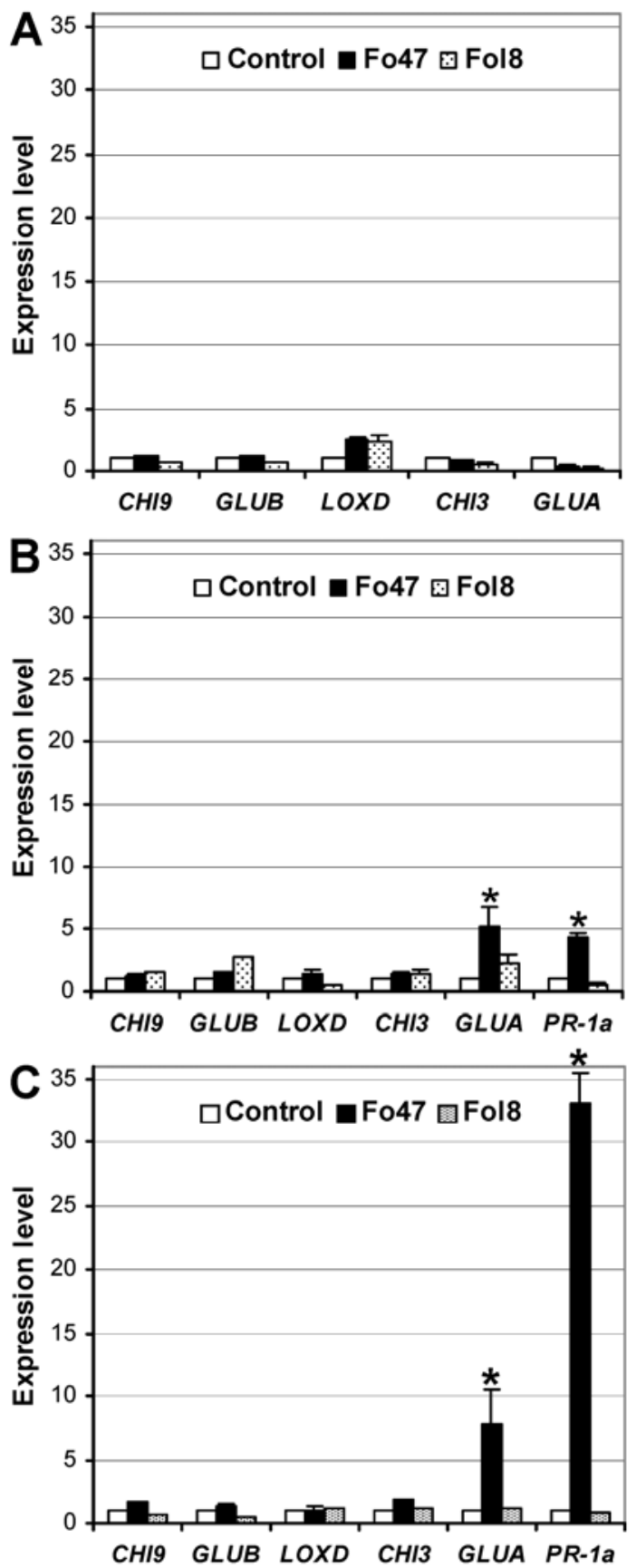

Fig. 5. Expression pattern of defense-related genes in tomato cotyledons. Tap root was inoculated with germinated microconidia of either Fo47 or Fol8. Cotyledons were collected A, 48; B, 72; and C, 96 h after root inoculation. Transcript accumulation of CHI9, GLUB, LOXD, CHI3, GLUA, and $P R 1-a$ genes was analyzed by reverse-transcription quantitative polymerase chain reaction. Results shown are from one representative experiment out of three. Bars represent mean expression levels normalized by the quantification cycle $(\mathrm{Cq})$ geometric average from the genes EF1 and $P P 2 A C S$ and referred to the noninoculated control as $2^{-\Delta \Delta \mathrm{Cq}}$ with standard deviation bars (technical replicates $n=3$ ). Asterisks indicate statistically significant differences between roots inoculated with Fo47 or Fol8 (Newman-Keuls test at $P=0.05$ ). only ones to be overexpressed in the cotyledons 72 and $96 \mathrm{~h}$ postinoculation. In the root preinoculated with Fo47 and challenged with Fol8, the expression of $C H I 3, G L U A$, and PR-1a genes was clearly upregulated in comparison with control roots and roots inoculated by Fol8 alone. These results showed that root inoculation with the endophytic strain Fo47 potentiate the expression of three genes encoding extracellular PR proteins, potentially involved in the salicylic acid (SA)-dependent defense pathway.

These results fit with others dealing with priming of defense responses induced by nonpathogenic strains of $F$. oxysporum. Paparu and associates (2007) showed that the $P R-1$ gene was potentiated in roots inoculated with endophytic strains of $F$. oxysporum and challenged with $R$. similis, resulting in induced resistance of banana against the nematode. He and associates
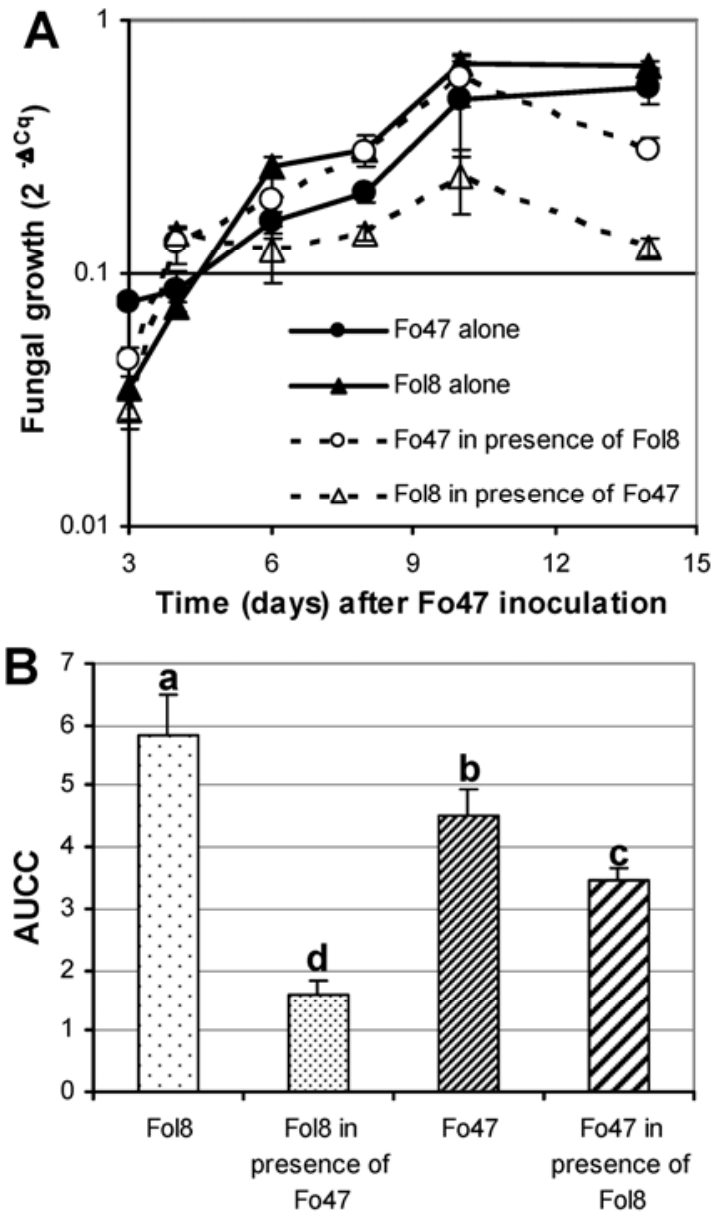

Fusarium strains

Fig. 6. Tomato root colonization by the protective strain Fo47 and the pathogenic strain Fol8, inoculated alone or together on the tap root as a suspension of 150 germinated microconidia. Fo47 was inoculated at J0 and Fol8 2 days later (J2), the two fungi being inoculated at different locations on the root. Quantification of the fungi was assessed by quantitative polymerase chain reaction using specific molecular markers sequencecharacterized amplified region (SCAR) for Fo47 and SIX1 for Fol8. Results shown are from one experiment out of two. The standard deviation was calculated from three technical replicates. A, Kinetics of root colonization within time: Fo47 alone (closed circle and solid line), Fol8 alone (closed square and solid line), Fo47 in the presence of Fol8 (open circle and dashed line), and Fol8 in the presence of Fo47 (open square and dashed line). Fungal growth was expressed as the relative difference between quantification cycle (Cq) of Fo47 SCAR amplicons or Fol8 SIX1 amplicons and $\mathrm{Cq}$ of tomato $\beta$-tubulin gene amplicons used as representative of root biomass $\left(2^{-\Delta \mathrm{Cq}}\right)$. B, Areas under the colonization curves (AUCC). Data with different letters are significantly different (NewmanKeuls test at $P=0.05$ ). 
(2002) showed that nonpathogenic strains of $F$. oxysporum induced systemic resistance of asparagus challenged with $F$. oxysporum f. sp. asparagi. This induced resistance was correlated with an upregulation of SA-responsive genes and the involvement of an SA-dependent signaling pathway was confirmed by using SA biosynthesis inhibitors (He and Wolyn 2005). Other studies showed that an SA-dependent defense pathway was involved in induced resistance to Fusarium diseases. Mandal and associates (2009) demonstrated that exogenous application of SA through root feeding can induce tomato resistance against $F$. oxysporum $\mathrm{f}$. sp. lycopersici. Edgar and associates (2006) showed that treatment of $A$. thaliana with SA prior to inoculation significantly increased resistance of plants to Fusarium diseases. Based on these articles, it can be suggested that the SA-dependent defense pathway is involved in the priming capacity of Fo47. Involvement of this pathway needs to be confirmed by the use of SA inhibitors or of tomato mutants impaired in the SA-signaling pathway. However, mechanisms involved in plant immunity are very complex and involved several pathways. Indeed, both the pathogen and the protective strain, inoculated separately, induced a transient activation of $C H I 9, G L U B$, and $L O X D$ genes, clearly observed $72 \mathrm{~h}$ after inoculation. In tomato, $C H I 9$ and $G L U B$ genes are involved in the defense signaling pathways regulated by jasmonic acid (Puthoff et al. 2010). The LOXD gene encoding a lipoxygenase is clearly involved in oxylipin biosynthesis directly related to the jasmonic acid pathway. Similarly, Kidd and associates (2011) showed that jasmonate-dependent defense genes (PDF1.2 and HEL) are induced by $F$. oxysporum in both roots and leaves of Arabidopsis.

Several studies suggested that priming could reduce the pathogen growth in the plant tissues (Ahn et al. 2011; Brotman et al. 2012; Gallou et al. 2011). Concerning Fo47, its effect on the growth of the pathogen in roots had already been suggested (Eparvier and Alabouvette 1994) but not accurately demonstrated because the tools necessary to specifically quantify Fo47 and the pathogen colonizing the same root were not available. Moreover, in the cited study, growth reduction was attributed to competition, because both fungi were inoculated together in the rhizosphere. To determine whether priming reduces the root colonization by the pathogenic strain, an in vitro experimental design has been set up to inoculate the two fungi at different locations on the tomato root. Microscopic observations (data not shown) showed that there was no direct interaction between the two fungi during the time course of the experiment. The hyphae of each fungus extending at the root surface did not reach each other, excluding competition between the protective and the pathogenic strain. For the first time, the use of specific markers and qPCR allowed the specific quantification of the biomass of each strain in the same root. Results showed that preinoculation of Fo47 on the tap root induced a significant reduction of the pathogen growth in the root. To our knowledge, this is the first report showing a relation between root colonization by a protective strain of $F$. oxysporum and a reduced colonization of the root by the pathogenic $F$. oxysporum through priming of defense responses. It has already been reported that root inoculation with growth-promoting rhizobacteria (Ahn et al. 2011) or Trichoderma spp. (Moreno et al. 2009) resulted in a reduction of the population density of bacterial or fungal pathogens colonizing leaves. By contrast, there is little information related to the reduced growth of a root pathogen in response to plant-induced resistance. Moreno and associates (2009) showed a correlation between the density of Trichoderma koningiopsis applied on the root and the percentage of stem fragments colonized by $F$. oxysporum f. sp. radicis lycopersici but they did not quantify the fungal growth in the roots. Shcherbakova and associates (2011) determined ergosterol content in tomato roots and stems to quantify the fungal growth in tomato protected from Fusarium wilt by inoculation of a nonpathogenic $F$. sambucinum. Although ergosterol content measurement is not specific to the pathogen, the authors concluded that protection against the wilt agent was related to limitation of the pathogen growth. Thus, to our knowledge, this study is the first to report an experiment where a pathogenic and a protective strain of $F$. oxysporum were quantified in the same root. Moreover, the reduced growth of the pathogenic strain was not due to direct antagonism between the two fungi but to a plant-mediated phenomenon.

The results showed that Fo47, applied on the root, induced in the cotyledons an overexpression of genes GLUA and $P R-1 a$ encoding PR proteins. This invites us to study whether Fo47 can induce resistance against foliar pathogens. Only Veloso and Diaz (2012) considered this question, showing that Fo47, which protected pepper against Verticillium wilt, was not effective against Botrytis cinerea. However, a strain of $F$. oxysporum f. sp. lycopersici inoculated on roots protected pepper against B. cinerea (Diaz et al. 2005). It must be stressed that induced resistance depends on many different factors; among them, the biocontrol strain, the pathogenic strain, and the plant species play a major role (Conn et al. 2008; Lorito et al. 2010; Van der Ent et al. 2009).

This study used tomato, a plant of economic interest, and Fo47, one of the most studied biological control agents, to demonstrate that, in addition to competition for nutrients (already well established), priming of plant defense is one of the mechanisms by which Fo47 controls Fusarium wilt.

\section{MATERIALS AND METHODS}

\section{Fungal material and inoculum preparation.}

The strains used in this study were the protective strain Fo47, isolated from a suppressive soil and transformed with the green fluorescent protein gene; and the pathogenic strain Fol8 (race 1), isolated from a diseased tomato stem and transformed with the DsRed2 gene. Both fungal strains were stored as a suspension of microconidia in $25 \%$ ( vol $/ \mathrm{vol})$ glycerol at $-80^{\circ} \mathrm{C}$, under the references MIAE00067 for Fo47 and MIAE00835 for Fol8 in the collection "Microorganisms of Interest for Agriculture and Environment" (MIAE; INRA Dijon, France).

Tomato roots were inoculated with germinated microconidia. Germinated microconidia with germ tubes 100 to $160 \mu \mathrm{m}$ long were prepared as described by Aimé and associates (2008).

\section{Plant material, growth conditions, and inoculation procedures.}

In order to test whether the biocontrol agent Fo47 induces a priming effect and reduces the colonization by the pathogenic strain Fol8, 'Montfavet 63-5' tomato, susceptible to Fusarium wilt, was used. Tomato seed were surface sterilized in $1.25 \%$ sodium hypochlorite for $20 \mathrm{~min}$ and rinsed three times in sterile distilled water. Seed were placed on Hoagland agar medium (Hoagland and Arnon 1950) distributed in plates. There were seven seeds per plate; six seedlings were used for the DNA or RNA extraction and one was observed under an epifluorescent microscope to control root colonization. An aluminum sheet was placed over the lid to prevent light from reaching the roots. The plates were placed in a growth chamber under controlled conditions: $23^{\circ} \mathrm{C}$ during the night and $25^{\circ} \mathrm{C}$ during the day, with a night and day cycle of 8 and $16 \mathrm{~h}$, respectively, and a light intensity of $225 \mu \mathrm{mE} \mathrm{m} \mathrm{m}^{-2} \mathrm{~s}^{-1}$.

Five days after sowing, tap roots were inoculated with Fo47 or Fol8 by depositing $2.5 \mu \mathrm{l}$ of suspension containing 150 germinated microconidia, spread at the root surface, $1 \mathrm{~cm}$ above the root apex. Two days later, two sets of plants noninoculated 
or preinoculated with Fo47 were inoculated with Fol8 according to the same procedure, except that germinated microconidia were deposited $1 \mathrm{~cm}$ below the hypocotyl. The plates were incubated in a growth chamber as described above.

\section{Selection of reference genes \\ for normalizing gene expression in tomato plants during infection with $\boldsymbol{F}$. oxysporum.}

To identify the reference genes suitable for normalization of RT-qPCR data, a set of six candidate reference genes $(T U B$, $G A P D H, E F 1, P P 2 A C S, A C T$, and $U B I$ ) was selected. The expression stability of the candidate reference genes across biological samples was evaluated using geNorm (version 3.5; VBA applet for Microsoft Excel 2000/XP/2003, version 3.5) following the author's recommendations. Furthermore, to estimate the optimal number of internal control genes required, normalization factors were calculated by stepwise inclusion of the most stably expressed genes (Vandesompele et al. 2002).

\section{Analysis of defense gene expression using RT-qPCR.}

The differential expression of genes CHI3, CHI9, GLUA, GLUB, LOXD, PR-1a, P69G, PAL, CHS1, and CHS2 was analyzed by RT-qPCR in the roots and cotyledons. Six roots and six cotyledons, belonging to six seedlings, were sampled 48, 72 , and $96 \mathrm{~h}$ after root inoculation with either Fo47 or Fol8 alone. Roots were sampled 24 and $48 \mathrm{~h}$ after inoculation with Fol8 in the following treatments: i) roots inoculated with Fo47 and, 2 days later, postinoculated with Fol8; or ii) roots noninoculated with Fo47, then inoculated with Fol8. Three independent experiments were performed.

Total RNA was extracted from $100 \mathrm{mg}$ of plant material originating from roots or cotyledons, following the protocol from the RNeasy plant mini kit (Qiagen GmbH, Hilden, Germany). Total RNA was treated by DNase using RQ1 RNaseFree DNase (Promega Corp., Madison, WI, U.S.A.). The RNA quantity in the samples was determined by spectrophotometry. Only the RNA samples with an absorbance ratio $(260 \mathrm{~nm} / 280$ $\mathrm{nm})$ greater than 1.8 were used for analysis. The integrity of RNA samples was assessed by electrophoresis on $1.5 \%$ agarose gel. First-strand cDNA was synthesized from $1 \mu \mathrm{g}$ of total RNA using the ImProm-II Reverse Transcription System (Promega Corp.) according to the manufacturer's instructions. Each sample was diluted 50 -fold and stored at $-20^{\circ} \mathrm{C}$ in 10 mM Tris buffer, $\mathrm{pH}$ 7.5.

qPCR reactions were carried out with $5 \mu$ of $1 / 50$ diluted RT products, $0.5 \mu \mathrm{M}$ each primer, $10 \mu \mathrm{l}$ of the SYBR green

Table 1. Primer pairs used in reverse-transcription quantitative polymerase chain reaction to amplify candidate reference and target genes of tomato

\begin{tabular}{|c|c|c|c|}
\hline Target gene & Primer sequence $\left(5^{\prime}-3^{\prime}\right)$ & Amplicon length (bp) & Accession number $^{\mathbf{a}}$ \\
\hline \multirow[t]{2}{*}{ LeTUB } & For AACCTCCATTCAGGAGATGTTT & & \\
\hline & Rev TCTGCTGTAGCATCCTGGTATT & 180 & DQ205342 \\
\hline \multirow[t]{2}{*}{ LeEF1 } & For GGAACTTGAGAAGGAGCCTAAG & & $\ldots$ \\
\hline & Rev CAACACCAACAGCAACAGTCT & 158 & X14449 \\
\hline \multirow[t]{2}{*}{ LeGAPDH } & For CTGCTCTCTCAGTAGCCAACAC & $\ldots$ & $\ldots$ \\
\hline & Rev CTTCCTCCAATAGCAGAGGTTT & 157 & TC198136* \\
\hline \multirow[t]{2}{*}{ LeACT } & For GAAATAGCATAAGATGGCAGACG & & $\ldots$ \\
\hline & Rev ATACCCACCATCACACCAGTAT & 159 & TC194780* \\
\hline \multirow[t]{2}{*}{ LePP2ACS } & For GTCATCCTTTCAGGTACAAGCA & $\ldots$ & $\ldots$ \\
\hline & Rev AAGCTGATGGGCTCTAGAAATC & 149 & AY325817 \\
\hline \multirow[t]{2}{*}{ LeUBI } & For GGACGGACGTACTCTAGCTGAT & & \\
\hline & Rev AGCTTTCGACCTCAAGGGTA & 134 & TC193502* \\
\hline \multirow[t]{2}{*}{ LeCHI3 } & For TGCAGGAACATTCACTGGAG & $\ldots$ & $\ldots$ \\
\hline & Rev TAACGTTGTGGCATGATGGT & 248 & Z15141 \\
\hline \multirow[t]{2}{*}{ LeCHI9 } & For GAAATTGCTGCTTTCCTTGC & & \\
\hline & Rev CTCCAATGGCTCTTCCACAT & 235 & Z15140 \\
\hline \multirow[t]{2}{*}{ LeGLUA } & For GGTCTCAACCGCGACATATT & & \\
\hline & Rev CACAAGGGCATCGAAAAGAT & 250 & M80604 \\
\hline \multirow{2}{*}{ LeGLUB } & For TCTTGCCCCATTTCAAGTTC & & $\ldots$ \\
\hline & Rev TGCACGTGTATCCCTCAAAA & 202 & M80608 \\
\hline \multirow[t]{2}{*}{ LePR-1A } & For TCTTGTGAGGCCCAAAATTC & $\ldots$ & $\ldots$ \\
\hline & Rev ATAGTCTGGCCTCTCGGACA & 246 & AJ011520 \\
\hline \multirow[t]{2}{*}{ LeP69G } & For TGGTACACACACAGCAAGCA & & $\ldots$ \\
\hline & Rev ATCACTCGAACCACCTCCAC & 232 & DQ157774 \\
\hline \multirow[t]{2}{*}{ LeLOXD } & For CCTGAAATCTATGGCCCTCA & & $\ldots$ \\
\hline & Rev ATGGGCTTAAGTGTGCCAAC & 227 & U37840 \\
\hline \multirow[t]{2}{*}{ LePAL } & For ACGGGTTGCCATCTAATCTG & & $\ldots$ \\
\hline & Rev AGCTCTTTTCCTGGCTGAAA & 197 & M83314 \\
\hline \multirow[t]{2}{*}{ LeCHS1 } & For CCAAGGACTTGGCTGAGAAC & $\ldots$ & $\ldots$ \\
\hline & Rev TATCGGGGACAAGAGTTTGG & 228 & X55194 \\
\hline \multirow[t]{2}{*}{ LeCHS2 } & For GCCAAAACTTGGCAAAGAAG & & \\
\hline & Rev CAGCAAAGCAACCTTGTTGA & 194 & X55195 \\
\hline
\end{tabular}

${ }^{\text {a }}$ Primers were designed from gene sequences in GenBank or, when marked by an asterisk (*),The Institute for Genomic Research Gene Indices.

Table 2. Primer pairs designed from gene sequences (GenBank) and used in quantitative polymerase chain reaction to amplify Fo47, Fol8, and tomato $\beta$ tubulin

\begin{tabular}{llcc}
\hline Target sequence or gene & \multicolumn{1}{c}{ Primer sequence $\left(\mathbf{5}^{\prime} \mathbf{-} \mathbf{3}^{\prime}\right)$} & Amplicon length $(\mathbf{b p})$ & Source, accession number \\
\hline Fo47 SCAR & For CTGGTGCTCGCAGAAATGCT & $\ldots$ & $\ldots$ \\
& Rev GCATGCATCGAGCGAACAAC & 211 & Edel-Hermann et al. 2011 \\
SIX1 & For CTTCGGGTATGACGGTGTTT & $\ldots$ & $\ldots$ \\
& Rev TAGTGTTTGGAGGGCTTTGG & 182 & $\ldots$ \\
LeTUB & For AACCTCCATTCAGGAGATGTTT & $\ldots$ & $\ldots$ \\
& Rev TCTGCTGTAGCATCCTGGTATT & 180 & DQ205342 \\
\hline
\end{tabular}

\footnotetext{
${ }^{\text {a }} \mathrm{SCAR}=$ sequence-characterized amplified region
} 
master mix (Quanti Tech SYBR Green kit; Qiagen GmbH), and Mol Bio-grade water (5 Prime GmbH, Hamburg, Germany) in a final volume of $20 \mu \mathrm{l}$. The primers for candidate reference and target genes (Table 1) were designed by Primer3 software (Applied Biosystems, Foster City, CA, U.S.A.), based on tomato mRNA sequences deposited in GenBank or The Institute for Genomic Research Gene Indices databases. In the negative control, cDNA was replaced by Mol Bio-grade water. qPCR reactions were performed on an ABI PRISM 7900HT Sequence Detection System (Applied Biosystems). Amplification reactions were performed with the following program: an initial denaturation step at $95^{\circ} \mathrm{C}$ for $15 \mathrm{~min}$; followed by 40 cycles of denaturation for $15 \mathrm{~s}$ at $95^{\circ} \mathrm{C}$, annealing for $30 \mathrm{~s}$ at $58^{\circ} \mathrm{C}$, and extension for $30 \mathrm{~s}$ at $72^{\circ} \mathrm{C}$; at the end of which the fluorescence was measured $\left(30 \mathrm{~s}\right.$ at $\left.79^{\circ} \mathrm{C}\right)$. The specificity of amplicons was checked by melting-curve analysis at the end of the PCR run over the range of 72 to $95^{\circ} \mathrm{C}$. The generated melting curves showed a single peak, indicating a single amplified product for all transcripts. In order to check PCR efficiency, standard curves based on $\mathrm{Cq}$ values versus log (cDNA dilution) were constructed using 10-fold dilution for each pair of selected primers. The efficiency of amplification for all tested genes was comparable; it varied from 92 to $100 \%$. For each RNA sample, the qPCR reaction was performed in triplicate.

Normalization of $\mathrm{Cq}$ values was achieved using the mean value of reference genes as endogenous control. The expression levels of target genes in noninoculated seedlings were used as calibrators. The $\mathrm{Cq}$ value for each gene was measured and the expression level of the genes in the different samples was calculated using the formula $2^{-\Delta \Delta \mathrm{Cq}}$ representing the $\mathrm{x}$-fold difference from the calibrator (Livak and Schmittgen 2001). The experiment was repeated three times and, within each experiment, results were compared by analysis of variance (ANOVA) followed by the Newman and Keuls test at $P=0.05$.

\section{Quantification of tomato root colonization by Fo47 and Fol8 using qPCR.}

Root colonization by Fo47 and Fol8 was quantified by qPCR tagging specific markers of the strain Fo47 SCAR (EdelHermann et al. 2011) and the gene encoding the protein Six 1 secreted in xylem 1 (Rep et al. 2004). Root colonization by the fungi was quantified in the following treatments: i) root inoculated with Fo47 alone; ii) root inoculated with Fo47 and, 2 days later, postinoculated with Fol8; and iii) root noninoculated with Fo47, then inoculated with Fol8. Six tomato roots were harvested 3, 4, 6, 8, 10, and 14 days after Fo47 inoculation. The experiment was repeated once.

At each sampling time, six frozen roots $(100 \mathrm{mg})$ were ground in liquid nitrogen and DNA was extracted and purified using the DNeasy plant mini kit (Qiagen GmbH). DNA quantity was measured by spectrophotometry and DNA quality was verified by electrophoresis on $1.5 \%$ agarose gel. The DNA samples were stored at $4^{\circ} \mathrm{C}$. For each sample, plant and fungal DNA was quantified by qPCR reaction performed on an ABI PRISM 7900HT sequence detection system (Applied Biosystems), using primers presented in Table 2. The PCR mixtures were set up as follows: $5 \mu \mathrm{l}$ of DNA ( $5 \mathrm{ng}), 0.5 \mu \mathrm{M}$ each primer, $10 \mu$ l of the SYBR green master mix (Quanti Tech SYBR Green kit; Qiagen GmbH), and Mol Bio-grade water (5 Prime $\mathrm{GmbH}$ D-22767) in a final volume of $20 \mu \mathrm{l}$. In the negative controls, DNA was replaced by Mol Bio-grade water and all the needed controls were included: fungal DNA extracted from germinated microconidia and plant DNA extracted from noninoculated plants. The following amplification program was used: $15 \mathrm{~min}$ at $95^{\circ} \mathrm{C}$ followed by 35 cycles of denaturation for $15 \mathrm{~s}$ at $95^{\circ} \mathrm{C}$, annealing for $30 \mathrm{~s}$ at $60^{\circ} \mathrm{C}$, and extension for $30 \mathrm{~s}$ at $72^{\circ} \mathrm{C}$. The specificity of amplicons was checked by melting curve analysis at the end of the PCR run over the range of 72 to $95^{\circ} \mathrm{C}$. For each DNA sample, the qPCR reaction was performed in triplicate.

The root colonization by Fo47 and Fol8 was expressed as the relative difference between Cq of Fo47 SCAR amplicons or Fol8 SIX1 amplicons and Cq of tomato TUB gene amplicons used as representative of root biomass $\left(2^{-\Delta \mathrm{Cq}}\right.$ calculation according to Livak and Schmittgen 2001). The experiment was repeated once and, within each experiment, results were compared by ANOVA followed by Newman and Keuls test at $P=$ 0.05 .

\section{LITERATURE CITED}

Ahn, I. P., Lee, S. W., Kim, M. G., Park, S. R., Hwang, D. J., and Bae, S. C. 2011. Priming by rhizobacterium protects tomato plants from biotrophic and necrotrophic pathogen infections through multiple defense mechanisms. Mol. Cells 32:7-14.

Aimé, S., Cordier, C., Alabouvette, C., and Olivain, C. 2008. Comparative analysis of PR gene expression in tomato inoculated with virulent Fusarium oxysporum f. sp. lycopersici and the biocontrol strain $F$. oxysporum Fo47. Physiol. Mol. Plant Pathol. 73:9-15.

Alabouvette, C. 1986. Fusarium-wilt suppressive soils from the Châteaurenard region: Review of a 10-year study. Agronomie 6:273-284.

Alabouvette, C., Olivain, C., Migheli, Q., and Steinberg, C. 2009. Microbiological control of soil-borne phytopathogenic fungi with special emphasis on wilt-inducing Fusarium oxysporum. New Phytol. 184:529544.

Benhamou, N., Grenier, J., Asselin, A., and Legrand, M. 1989. Immunogold localization of $\beta$-1-3-glucanases in two plants infected by vascular wilt fungi. Plant Cell 1:1209-1221.

Benhamou, N., Joosten, M. H. A. J., and De Witt, P. J. G. M. 1990. Subcellular localization of chitinase and of its potential substrate in tomato root tissues infected by Fusarium oxysporum f. sp. radicis lycopersici. Plant Physiol. 92:1108-1120.

Brotman, Y., Lisec, J., Méret, M., Chet, I., Willmitzer, L., and Viterbo, A. 2012. Transcript and metabolite analysis of the Trichoderma-induced systemic resistance response to Pseudomonas syringae in Arabidopsis thaliana. Microbiology 158:139-146.

Cachinero, J. M., Hervas, A., Jimenez-Diaz, R. M., and Tena, M. 2002. Plant defence reactions against Fusarium wilt in chickpea induced by incompatible race 0 of Fusarium oxysporum f. sp. ciceris and nonhost isolates of F. oxysporum. Plant Pathol. 51:765-776.

Conn, V. M., Walker, A. R., and Franco, C. M. M. 2008. Endophytic actinobacteria induce defense pathways in Arabidopsis thaliana. Mol. Plant-Microbe Interact. 21:208-218.

Couteaudier, Y., and Alabouvette, C. 1990. Quantitative comparison of Fusarium oxysporum competitiveness in relation with carbon utilization. FEMS (Fed. Eur. Microbiol. Soc.) Microbiol. Ecol. 74:261-268.

Danhash, N., Wagemakers, C. A. M., Van Kan J. A. L., and De Wit, P. J. G. M. 1993. Molecular characterisation of four chitinase cDNAs obtained from Cladosporium fulvum-infected tomato. Plant Mol. Biol. 22:10171029.

Diaz, J., Silvar, C., Varela, M. M., Bernal, A., and Merino, F. 2005. Fusarium confers protection against several mycelial pathogens of pepper plants. Plant Pathol. 54:773-780.

Edel-Hermann, V., Aimé, S., Cordier, C., Olivain, C., Steinberg, C., and Alabouvette, C. 2011. Development of a strain specific real-time PCR assay for the detection and quantification of the biological control agent Fo47 in root tissues. FEMS (Fed. Eur. Microbiol. Soc.) Microbiol. Lett. 322:34-40

Edgar, C. I., McGrath, K. C., Dombrecht, B., Manners, J. M., Maclean, D. C., Schenk, P. M., and Kazan, K. 2006. Salicylic acid mediates resistance to the vascular wilt pathogen Fusarium oxysporum in the model host Arabidopsis thaliana. Australas. Plant Pathol. 35:581-591.

Enkerli, J., Gisi, U., and Mösinger E. 1993. Systemic acquired resistance to Phytophthora infestans in tomato and the role of pathogenesis related proteins. Physiol. Mol. Plant Pathol. 43:161-171.

Eparvier, A., and Alabouvette, C. 1994. Use of ELISA and GUS-transformed strains to study competition between pathogenic and non-pathogenic Fusarium oxysporum for root colonization. Biocontrol Sci. Technol. 4:35-47.

Expósito-Rodríguez, M., Borges, A. A., Borges-Pérez, A., and Pérez, J. A. 2008. Selection of internal control genes for quantitative real-time RTPCR studies during tomato development process. BMC Plant Biol. 8:131. doi:10.1186/1471-2229-8-131. Online publication.

Gallou, A., Mosquera, H. P. L., Cranenbrouk S., Suárez J. P., and Declerck, 
S. 2011. Mycorrhiza induced resistance in potato plantlets challenged by Phytophthora infestans. Physiol. Mol. Plant Pathol. 76:20-26.

Ghareeb, H., Bozsó, Z., Ott, P. G., and Wydra, K. 2011. Silicon and Ralstonia solanacearum modulate expression stability of housekeeping genes in tomato. Physiol. Mol. Plant Pathol. 75:176-179.

He, C. Y., and Wolyn, D. J. 2005. Potential role for salicylic acid in induced resistance of asparagus roots to Fusarium oxysporum f. sp. asparagi. Plant Pathol. 54:227-232.

He, C. Y., Hsiang, T., and Wolyn, D. J. 2002. Induction of systemic disease resistance and pathogen defense responses in Asparagus officinalis inoculated with nonpathogenic strains of Fusarium oxysporum. Plant Pathol. 51:225-230.

Heitz, T., Bergey, D. R., and Ryan, C. A. 1997. A gene encoding a chloroplast-targeted lipoxygenase in tomato leaves is transiently induced by wounding, sytemin, and methyl jasmonate. Plant Physiol. 114:10851095 .

Hoagland, D. R., and Arnon D. I. 1950. The water-culture method for growing plants without soil. Univ. Calif. Agric. Exp. Stn. 347:1-32.

Joosten, M. H. A. J., and De Witt, P. J. G. M. 1989. Identification of several pathogenesis-related proteins in tomato leaves inoculated with Cladosporium fulvum (syn. Fulvia fulva) as $1,3-\beta$-glucanases and chitinases. Plant Physiol. 89:945-951.

Kavroulakis, N., Papadopoulou, K. K., Ntougias, S., Zervakis, G. I., and Ehaliotis, C. 2006. Cytological and other aspects of pathogenesisrelated gene expression in tomato plants grown on a suppressive compost. Ann. Bot. 98:555-564.

Kidd, B. N., Kadoo, N. Y., Dombrecht, B., Tekeoğlu, M., Gardiner, D. M., Thatcher, L. F., Aitken, E. A. B., Schenk, P. M., Manners, J. M., and Kazan, K. 2011. Auxin signaling and transport promote susceptibility to the root-infecting fungal pathogen Fusarium oxysporum in Arabidopsis. Mol. Plant-Microbe Interact. 24:733-748.

Kravchuk, Z., Vicedo, B., Flors, V., Camaňes, G., González-Bosch, C., and García-Agustín, P. 2011. Priming for JA-dependent defenses using hexanoic acid is an effective mechanism to protect Arabidopsis against B. cinerea. J. Plant Physiol. 168:359-366.

Livak, K. J., and Schmittgen, T. D. 2001. Analysis of relative gene expression data using real-time quantitative PCR and the $2^{-\Delta \Lambda \mathrm{CT}}$ method. Methods 25:402-408.

Lorito, M., Woo, S. L., Harman, G. E., and Monte, E. 2010. Translational research on Trichoderma: From 'omics to the field. Annu. Rev. Phytopathol. 48:395-417.

Løvdal, T., and Lillo, C. 2009. Reference gene selection for quantitative real-time PCR normalization in tomato subjected to nitrogen, cold, and light stress. Anal. Biochem. 387:238-242.

Mandal, S., Mallick, N., and Mitra, A. 2009. Salicylic acid-induced resistance to Fusarium oxysporum f. sp. lycopersici. Plant Physiol. Biochem. 47:642-649.

Mascia, T., Santovito, E., Gallitelli, D., and Cilio, F. 2010. Evaluation of reference genes for quantitative reverse-transcription polymerase chain reaction normalization in infected tomato plants. Mol. Plant Pathol. 11:805-816

Massoud, K., Barchietto, T., Le Rudulier, T., Pallandre, L., Didierlaurent, L., Garmier, M., Ambard-Bretteville, F., Seng, J. M., and Saindrenan P. 2012. Dissecting phosphite-induced priming in Arabidopsis infected with Hyaloperonospora arabidopsidis. Plant Physiol. 159:286-298.

Moreno, C. A., Castillo, F., González, A., Bernal, D., Jaimes, B. C., Chaparro, M., González, C., Rodriguez, F., Restrepo, S., and Cotes, A. M. 2009. Biological and molecular characterization of the response of tomato plants treated with Trichoderma koningiopsis. Physiol. Mol. Plant Pathol. 74:111-120.

Nagao, H., Couteaudier, Y., and Alabouvette, C. 1990. Colonization of sterilized soil and flax roots by strains of Fusarium oxysporum and Fusarium solani. Symbiosis 9:343-354.

O’Donnell, K., Gueidan, C., Sink, S., Johnston, P. R., Crous, P. W., Glenn , A., Riley, R., Zitomer, N. Colyer, P., Waalwijk, C., van der Lee, T., Moretti , A., Kang, S., Kim, H., Geiser, D. M., Juba, J. H. , Baayen, R. P., Cromey, M. G., Bithell, S., Sutton, D. A., Skovgaard, K., Ploetz, R., Kistler, H. C. , Elliott, M., Davis, M., and Sarver, B. A. J. 2009. A twolocus DNA sequence database for typing plant and human pathogens within the Fusarium oxysporum species complex. Fungal Genet. Biol. 46:936-948

Olivain, C., Steinberg, C., and Alabouvette, C. 1995. Evidence of induced resistance in tomato inoculated by non-pathogenic strains of Fusarium oxysporum. Pages 427-430 in: Environmental Biotic Factors in Integrated Plant Disease Control. M. Manka, ed. The Polish Phytopathological Society, Poznan, Poland.

Olivain, C., Humbert, C., Nahalkova, J., Fatehi, J., L'Haridon, F., and Alabouvette, C. 2006. Colonization of tomato root by pathogenic and non pathogenic Fusarium oxysporum strains inoculated together and separately into the soil. Appl. Environ. Microbiol. 72:1523-1531.

Paparu, P., Dubois, T., Coyne, D., and Viljoen, A. 2007. Defense-related gene expression in susceptible and tolerant bananas (Musa spp.) following inoculation with non-pathogenic Fusarium oxysporum endophytes and challenge with Radopholus similis. Physiol. Mol. Plant Pathol. 71:149-157.

Pieterse, C. M. J., Van Wees S. C. M., Hoffland E., Van Pelt J. A., and Van Loon L. C. 1996. Systemic resistance in Arabidopsis induced by biocontrol bacteria is independent of salicylic acid accumulation and pathogenesis-related gene expression. Plant Cell 8:1225-1237.

Puthoff, D. P., Holzer, F. M., Perring, T. M., and Walling, L. L. 2010. Tomato pathogenesis-related protein genes are expressed in response to Trialeurodes vaporarium and Bemisia tabaci biotype B feeding. J. Chem. Ecol. 36:1271-1285.

Rep, M., Van der Does, H. C., Meijer, M., Van Wijk, R., Houterman, P. M., Dekker, H. L., De Koster, C. G., and Cornelissen, B. J. C. 2004. A small, cysteine-rich protein secreted by Fusarium oxysporum during colonization of xylem vessels is required for I-3-mediated resistance in tomato. Mol. Microbiol. 53:1373-1383.

Shcherbakova, L. A., Nazarova, T. A., Mikityuk, O. D., and Fravel, D. R. 2011. Fusarium sambucinum isolate FS-94 induces resistance against Fusarium wilt of tomato via activation and priming of a salicylic aciddependent signaling system. Russ. J. Plant Pathol. 58:808-818.

Shoresh, M., Yedidia, I., and Chet, I. 2005. Involvement of jasmonic acid/ethylene signalling pathway in the systemic resistance induced in cucumber by Trichoderma asperellum T203. Phytopathology 95:76-84.

Tucci, M., Ruocco, M., De Masi, L., De Palma, M., and Lorito, M. 2011. The beneficial effect of Trichoderma spp. on tomato is modulated by the plant genotype. Mol. Plant Pathol. 12:341-354.

Uehara, T., Sugiyama, S., Matsuura, H., Arie, T., and Masuta, C., 2010. Resistant and susceptible responses in tomato to cyst nematode are differentially regulated by salicylic acid. Plant Cell Physiol. 51:1524 1536.

Van der Ent, S., Van Wees, S. C. M., and Pieterse, C. M. J. 2009. Jasmonate signaling in plant interactions with resistance-inducing beneficial microbes. Phytochemistry 70:1581-1588.

Vandesompele, J., De Preter, K., Pattyn, F., Poppe, B., Van Roy, N., De Paepe, A., and Speleman, F. 2002. Accurate normalization of real-time quantitative RT-PCR data by geometric averaging of multiple internal control genes. Genome Biol. 3:research0034.1-0034.11

Van Kan, J. A. L., Jooosten, M. H. A. J., and Wagemakers, C. A. M. 1992. Differential accumulation of mRNAs encoding extracellular and intracellular PR proteins in tomato induced by virulent and avirulent races of Cladosporium fulvum. Plant Mol. Biol. 20:513-527.

Veloso, J., and Diaz, J. 2012. Fusarium oxysporum Fo47 confers protection to pepper plants against Verticillium dahliae and Phytophthora capsici, and induces the expression of defense genes. Plant Pathol. 61:281-288.

Wróbel-Kwiatkowska, M., Lorenc-Kubula, K., Starzycki, M., Oszmiańki, J., Kepczyńska E., and Szopa J. 2004. Expression of $\beta$-1,3-glucanase in flax causes increased resistance to fungi. Physiol. Mol. Plant Pathol. 65:245-256.

Zamioudis, C., and Pieterse, C. M. J. 2012. Modulation of host immunity by beneficial microbes. Mol. Plant-Microbe Interact. 25:139-150.

Zimmerli, L., Jakab, C., Metraux, J. P., and Mauch-Mani, B. 2000. Potentiation of pathogen-specific defense mechanisms in Arabidopsis by $\beta$-aminobutyric acid. Proc. Natl. Acad. Sci. U.S.A. 97:12920-12925.

\section{AUTHOR-RECOMMENDED INTERNET RESOURCES}

geNorm database: medgen.ugent.be/ jvdesomp/genom

INRA UMR Microbiology Soil and Environment MIAE database: www2.dijon.inra.fr/umrmse

Primer3 v. 0.4.0 software: fokker.wi.mit.edu/primer3/input.htm 